\title{
RECENT CLINICAL EXPERIENCES WITH CHIKUNGUNYA
}

QUAZI TARIKUL ISLAM ${ }^{1}$, M MAJUMDER ${ }^{2}$, A BASIT $^{3}$

\section{Introduction}

Chikungunya fever is an emerging viral disease transmitted to humans by mosquitoes. Chikungunya Virus (CHIKV) is an arbovirus of the alphavirus genus (Togaviridae family). The Aedesaegypti and Aedesalbopictus mosquitoes are the main vectors responsible for transmission of Chikungunya. Chikungunya fever displays interesting epidemiological profiles: major epidemics appear and disappear cyclically, usually with an inter-epidemic period of 7-8 years and sometimes as long as 20 years ${ }^{1}$. We have our small three outbreaks in 2008 at Rajshahi( Northern part, near Indian border) in 2011 at Dohar near Dkaka city, Palpara in 2012 near Dhaka $^{2,3}$. In 2017, Bangladesh experienced a large outbreak of Chikungunya just in early-monsoon in March when there was unexpected rain fall. This Short communication is published to give an idea about this recent outbreak.

\section{Method}

Data was collected from 138 patients starting from early April up till June 2017. Data was only collected from patients who presented with fever and joint pain and in whom we had ruled out Dengue by doing Dengue NS1 antigen done within 5 days of start of fever. The diagnosis of Chikungunya was confirmed by doing either PT-PCR for Chikungunya, done within 5 days of onset of fever or by doing Rapid Diagnostic Test (RDT) SD Biosensor (sensitivity 100\%, Specificity $97.7 \%$ ) equivalent to ELISA, manufactured by Republic of Korea on formula of MT prometd $\mathrm{GmbH}$, Germany, for Chikungunya serology (IgM) after 10 days of fever onset, although it is said that seroconversion occurs after 7 days, we did serology after 10 days to reduce the possibility of false negative results.

\section{Result}

Out of the 138 patients, age distribution of the patients were 40-49 (21\%), 20-29 (20\%), 60-69 (18\%),
30-39 (17\%), 50-59 (8\%), 10-19 (7\%), 70-79 (6\%), 8089 (1\%). 61\% patients were female, 39\% male. 30\% of patients lived on the $3^{\text {rd }}$ floor of their residence, followed by $18 \%$ on 2 nd, $15 \%$ on 4 th, $13 \%$ on 1 st, $8 \%$ on ground floor, $8 \%$ on $5^{\text {th }}$ and $5 \%$ living above $6^{\text {th }}$ floor. $31 \%$ presented on the $4^{\text {th }}$ day of fever, $28 \%$ on $3^{\text {rd }}$ day, $21 \%$ on $5^{\text {th }}$ day, $11 \%$ on $2^{\text {nd }}$ day and $6 \%$ on the $1^{\text {st }}$ day of fever. $34 \%$ of patients had a highest recorded temp of $103 æ \% \mathrm{~F}$, followed by $27 \% 104 æ \% \mathrm{~F}$, $27 \% 102 æ \% \mathrm{~F}, 5 \% 101 æ \% \mathrm{~F}, 2 \% 105 æ \% \mathrm{~F}$ and $2 \% 100$ $æ \% \mathrm{~F}$. Rash was present in only $38 \%$ of patients out of which $80 \%$ had generalized body rash and $20 \%$ had localized. $48 \%$ of patients had more $>10$ joints involved followed by $31 \%$ with 5 to 9 joints involved and $18 \%$ with $<5$ joints involved. $57 \%$ of patients had involvement of both large and small joints with 33\% only large joints and only $7 \%$ suffering from involvement of small joints of the hands and feet only. Only $24 \%$ patients had back pain, $83 \%$ complained of headache, $82 \%$ nausea and vomiting, 9\% cough, 5\% lymphadenopathy and 3\% abdominal pain.

\section{Discussion}

Acording to this study, people of middle age group were mostly infected by CHIKV during this outbreak $(76 \%)$, while the very young and elderly persons were less affected (14\%). Females were mostly infected than males. The findings are a little far from some other studies that state Chikungunya fever affecting all age groups and both genders are equally affected ${ }^{4-7}$ but in Bangladesh some research work showed this type of age and sex differentiation ${ }^{14}$.

A single floor measures 12-14 feet (2.27-3.67 meter) high on average. Our study shows that most persons infected by CHIKV were resident of above $3^{\text {rd }}$ floor of

1. Professor of Medicine, Popular Medical Collage

2. Registrar, Medicine, Popular Medical College

3. Asstt. Registrar, Popular Medical College Hospital

Correspondence: Dr. Quazi Tarikul Islam, Email : prof.tarik@gmail.com

Bangladesh J Medicine 2017; 28 : 104-106 
multistoried building which supports the fact of flight range studies that suggest that most female Ae. aegypti may spend their lifetime in or around the houses where they emerge as adults and they usually fly an average of 400 metres $^{9}$. Reliable information could not be found whether people leaving at ground level are less affected by aedes mosquitos yet this study supports this.

Presenting within 5 days of onset of fever was an inclusion criterion of this study. Most presented after $2^{\text {nd }}$ day of high fever with maximum others from 3rd to $5^{\text {th }}$ day of febrile illness. This is similar to the other epidemiological studies on CHIKV describing presentation as abrupt and sudden with high-grade fever (usually $102-105^{\circ} \mathrm{F}$ ) 4,5,6,7, 9, 10, 12, 13. But least number of patients presenting in the first day may be due to the fact that fever varies from low grade to high grade, lasting for 24 to 48 hours ${ }^{11}$ or may indicate an escalation of severity of symptoms that yet not has been observed. $96 \%$ patient presenting with initial temperature within $102-105{ }^{\circ} \mathrm{F}$ strongly supports previous study findings $4,7,9,12,13$.

Less than fifty percent presenting with body rash along with fever and joint pain resembles data of other studies 4-7, 9, 10. Though the result does not reflect body rash to be very common presentation as some studies claim 15, 16, 17 but the portion of individuals with rash is highly variable between studies 18,19 . Rash appearing all over body in maximum patients affecting body/ trunk is similar to studies done before 18,19 .

Majority of patients with arthritic manifestation in this study showed polyarthritis affecting large and small joints which supports data of many studies that claim "The joint pains are usually symmetric and occur most commonly in wrists, elbows, fingers, knees, and ankles but can also affect more-proximal joints" 20 . But it has dissimilarities with few other studies that state that "The Chikungunya viral polyarthropathy frequently involves the small joints of the hand, wrist" $7,10,21$

The additional symptoms of CHIKV infection in acute phase in this study included headache, nausea and vomiting, back pain, cough, lymphadenopathy and abdominal pain. Other study also support this finding 22 but rarer neurovirulence and neuroinvasiveness 7, 11 were not found in this study.

Hemorrhagic manifestations were not found though some studies claim that these are more frequently encountered in Asian subcontinent 7, 11

\section{References}

1. Chikungunya Fever, a re-emerging Disease in Asia http: / / www.searo.who.int/entity/emerging_ diseases/topics/Chikungunya/en/

2. Tsetsarkin KA, Vanlandingham DL, McGee CE, Higgs S (2007) A Single Mutation in Chikungunya Virus Affects Vector Specificity and Epidemic Potential. PLoSPathog 3: 30201.

3. Tsetsarkin KA, Weaver SC (2014) Sequential Adaptive Mutations Enhance Efficient Vector Switching by Chikununya Virus and its Epidemic Emergence. PLoSPathog 7: e1002412.

4. Mohan A. Chikungunya fever: clinical manifestations \& management. Indian J Med Res. 2006;124:4714. [PubMed]

5. Mohan A, Sharma SK. Chikungunya fever. In: Singal RK, editor. Medicine update. Mumbai: Association of Physicians of India; 2007. pp. 634-8.

6. Mohan A. Chikungunya fever strikes in Andhra Pradesh. Natl Med J India. 2006;19:240.

7. Simon F, Savini H, Parola P. Chikungunya: a paradigm of emergence and globalization of vectorborne diseases. Med Clin North Am. 2008;92:132343. ix. [PubMed]

8. Integrating vector control across diseases 1 October 2015

9. Powers AM, Logue $\mathrm{CH}$. Changing patterns of chikungunya virus: re-emergence of a zoonotic arbovirus. J Gen Virol. 2007;88:2363-77. [PubMed]

10. Fact Sheet, Chikungunya, Updated 2017

11. Guidelines on Clinical Management of Chikungunya Fever, WHO October 2008.

12. Deller JJ, Jr., Russell PK. Chikungunya disease. Am J Trop Med Hyg 1968; 17:107-11.

13. Halstead SB, Udomsakdi S, Singharaj P, Nisalak A. Dengue and chikungunya virus infection in man in Thailand, 1962-1964. III. Clinical

14. Selina Khatun, Apurba Chakraborty, Mahmudur Rahman, Nuzhat Nasreen Banu, Mohammad Mostafizur Rahman, S. M. Murshid Hasan. An Outbreak of Chikungunya in Rural Bangladesh, 2011. PLoS Negl Trop Dis 9(7): e0003907. doi:10.1371/journal.pntd.0003907

15. Taubitz W, Cramer JP, Kapaun A, et al. Chikungunya fever in travelers: clinical presentation and course. Clin Infect Dis 2007; 45:e1-4.

16. Queyriaux B, Simon F, Grandadam M, Michel R, Tolou H, Boutin JP. Clinical burden of chikungunya virus infection. Lancet Infect Dis 2008; 8:2-3. 
17. De Ranitz CM, Myers RM, Varkey MJ, Isaac ZH, Carey DE. Clinical impressions of chikungunya in Vellore gained from study of adult patients. Indian J Med Res 1965; 53:756-63.

18. Borgherini G, Poubeau P, Staikowsky F, et al. Outbreak of chikungunya on Reunion Island: early clinical and laboratory features in 157 adult patients. Clin Infect Dis 2007; 44:1401-7.

19. Inamadar AC, Palit A, Sampagavi VV, Raghunath S, Deshmukh NS. Cutaneous manifestations of chikungunya fever: observations made during a recent outbreak in south India. Int J Dermatol2008; 47:154-9.
20. Simon F, Parola P, Grandadam M, et al. Chikungunya infection: an emerging rheumatism among travelers returned from Indian Ocean islands. Report of 47 cases. Medicine 2007; 86: 123-37.

21. Simon F, Parola P, Grandadam M, Fourcade S, Oliver $\mathrm{M}$, Brouqui $\mathrm{P}$, et al. Chikungunya infection: an emerging rheumatism among travelers returned from Indian Ocean islands. Report of 47 cases. Medicine (Baltimore) 2007;86:123-37. [PubMed]

22. Kiwanuka N, Sanders EJ, Rwaguma EB, et al. O'nyong-nyong fever insouth-central Uganda, 19961997: clinical features and validation of aclinical case definition for surveillance purposes. Clin Infect Dis 1999;29:1243-50. 